\title{
Synthesis of $\mathrm{Ba}_{3} \mathrm{ZnNb}_{2} \mathrm{O}_{9}-\mathrm{Sr}_{3} \mathrm{ZnNb}_{2} \mathrm{O}_{9}$ solid solution and their dielectric properties
}

\author{
M THIRUMAL and A K GANGULI* \\ Department of Chemistry, Indian Institute of Technology, New Delhi 110 016, India
}

MS received 6 October 2001; revised 31 May 2002

\begin{abstract}
Oxides of the type, $\mathrm{Ba}_{3-x} \mathrm{Sr}_{x} \mathrm{ZnNb}_{2} \mathrm{O}_{9}(0 \leq x \leq 3)$, were synthesized by the solid state route. Oxides calcined at $1000^{\circ} \mathrm{C}$ show single cubic phase for all the compositions. The cubic lattice parameter (a) decreases with increase in $\mathrm{Sr}$ concentration from 4.0938(2) for $x=0$ to 4.0067(2) for $x=3$. Scanning electron micrographs show maximum grain size for the $x=1$ composition $(\sim 2 \mu \mathrm{m})$ at $1200^{\circ} \mathrm{C}$. Disks sintered at $1200^{\circ} \mathrm{C}$ show dielectric constant variation between 28 and 40 (at $500 \mathrm{kHz}$ ) for different values of $x$ with the maximum dielectric constant at $x=1$.
\end{abstract}

Keywords. Materials; oxides; X-ray diffraction; dielectric properties.

\section{Introduction}

Ceramic materials with reasonably high dielectric constant (25-40) associated with low dielectric loss at microwave frequencies are of interest because of their use as dielectric resonators in integrated microwave circuits as filters and oscillators (Plourde 1981). Search for materials having the optimum dielectric properties has led to numerous investigations of the oxide materials.

Among various families of oxides studied for dielectric applications, the oxides of the type $A\left(B_{1 / 3} B_{2 / 3}^{1}\right) O_{3}$ have been particularly of interest. The $A\left(B_{1 / 3} B_{2 / 3}^{1}\right) \mathrm{O}_{3}$ or $\mathrm{A}_{3} \mathrm{BB}_{2}^{1} \mathrm{O}_{9}$ type of perovskite oxides were first prepared by Roy (1954) and Galasso et al (1959). Oxides with $\mathrm{A}=\mathrm{Ba}, \mathrm{Sr} ; \mathrm{B}=\mathrm{Zn}, \mathrm{Mg}$ and $\mathrm{B}^{1}=\mathrm{Nb}$ and $\mathrm{Ta}$ have been found to have appropriate dielectric properties. $\mathrm{Ba}_{3} \mathrm{ZnTa}_{2} \mathrm{O}_{9}$ was the first low loss dielectric material reported (Kawashima et al 1983) for application at microwave frequencies. Since then several studies (Nomura et al 1982; Desu and O'Bryan 1985; Vincent et al 1993) on related oxides have been carried out on other tantalates. These oxides crystallize in the disordered cubic structure or in a hexagonally ordered structure.

Both $\mathrm{Ba}_{3} \mathrm{ZnNb}_{2} \mathrm{O}_{9}$ (BZN) (Hong et al 1996) and $\mathrm{Sr}_{3} \mathrm{ZnNb}_{2} \mathrm{O}_{9}(\mathrm{SZN})$ (Galasso and Pyle 1963) are reported to have hexagonally ordered perovskite structures. However, some earlier reports have shown that BZN shows disordered structure (Galasso and Pyle 1963; Endo et al 1987). An earlier study (Onoda et al 1982) on the solid solution $\mathrm{Ba}_{3-x} \mathrm{Sr}_{x} \mathrm{ZnNb}_{2} \mathrm{O}_{9}$, reported possibility of ordered structures at high $\mathrm{Sr}$ concentration for samples sintered at $1500^{\circ} \mathrm{C}$.

*Author for correspondence
In this paper, we report the synthesis, structural studies and phase relations in the temperature range 1200$1300^{\circ} \mathrm{C}$. We also discuss the dielectric data in the $50 \mathrm{~Hz}$ to $500 \mathrm{kHz}$ region for $\mathrm{Ba}_{3-x} \mathrm{Sr}_{x} \mathrm{ZnNb}_{2} \mathrm{O}_{9}$ sintered at relatively low temperatures $\left(1200^{\circ} \mathrm{C}\right)$. Our study aims to investigate the influence, if any, of $A$-site substitution on the $B$-site ordering in an attempt to obtain ordered perovskites at relatively low temperatures $\left(1200^{\circ} \mathrm{C}\right)$.

\section{Experimental}

The starting materials were $\mathrm{BaCO}_{3}(\mathrm{CDH}$, India, 99.5\%), $\mathrm{SrCO}_{3}(\mathrm{CDH}$, India, 98\%), $\mathrm{ZnO}(\mathrm{CDH}$, India, 99.5\%), $\mathrm{Al}_{2} \mathrm{O}_{3}$ (Aldrich, 99.7\%), and $\mathrm{Nb}_{2} \mathrm{O}_{5}$ (CDH, India, 99.5\%). Stoichiometric quantities were weighed, ground and calcined at $1000^{\circ} \mathrm{C}$ for $30 \mathrm{~h}$ with two intermittent grindings. The calcined powder was ground, pressed into pellets with $5 \%$ polyvinylalcohol (PVA) solution and at 4 ton pressure. These disks were preheated at $1000^{\circ} \mathrm{C}$ for $48 \mathrm{~h}$ followed by sintering at $1200^{\circ} \mathrm{C}$ for $24 \mathrm{~h}$ and used for dielectric measurements till $500 \mathrm{kHz}$. Sintering was also carried out on another set of samples at $1250^{\circ} \mathrm{C}$.

Powder X-ray diffraction (PXRD) study was carried out using a Bruker D8-Advance X-ray diffractometer at a scan speed of $2 \mathrm{deg} / \mathrm{min}$ using $\mathrm{CuK} \alpha$ radiation. Lattice parameters were calculated by a least square fit to the observed $d$-values. The grain size of the samples were obtained on sintered pellets by means of scanning electron microscopy (SEM) using a Cambridge Stereoscan 360 electron microscope. The bulk density of ceramics was measured by Archimedes method and the relative density was around $93 \%$ of theoretical density.

The dielectric constant and dielectric loss at low frequencies $(50 \mathrm{~Hz}-500 \mathrm{kHz})$ were measured using an 
HP 4284L LCR meter on well sintered disks with coated aluminium as electrodes.

\section{Results and discussion}

Single phases were obtained for all the compositions $\left(\mathrm{Ba}_{3-x} \mathrm{Sr}_{x} \mathrm{ZnNb}_{2} \mathrm{O}_{9}, 0 \leq x \leq 3\right)$ synthesized at $1000^{\circ} \mathrm{C}$. These oxides crystallize in the cubic structure and their lattice parameters are shown in table 1 . We observe that the lattice parameter " $a$ " systematically decreases with increase in the 'Sr' concentration. Figure 1 (inset) shows the plot of variation of lattice parameter with ' $x$ '. Note that $\mathrm{Sr}^{2+}$ (XII) has a smaller ionic radii than that of $\mathrm{Ba}^{2+}$ (XII) (Shannon 1976). In order to improve the ordering of cations in these oxides the powders were pressed into disks and sintered at higher temperatures. The disks were

Table 1. Lattice parameters for $\mathrm{Ba}_{3-x} \mathrm{Sr}_{x} \mathrm{ZnNb}_{2} \mathrm{O}_{9}$ system calcined at $1000^{\circ} \mathrm{C}$ for $30 \mathrm{~h}$.

\begin{tabular}{lc}
\hline $\begin{array}{c}\text { Composition, } \\
x\end{array}$ & $\begin{array}{c}a_{\text {cubic }} \\
(\AA)\end{array}$ \\
\hline 0.0 & $4 \cdot 0938(2)$ \\
0.5 & $4.0845(2)$ \\
1.0 & $4.0699(1)$ \\
1.25 & $4 \cdot 0625(4)$ \\
1.50 & $4.0539(1)$ \\
1.75 & $4.0452(3)$ \\
2.0 & $4 \cdot 0341(5)$ \\
2.5 & $4.0163(4)$ \\
3.0 & $4.0067(2)$ \\
\hline
\end{tabular}

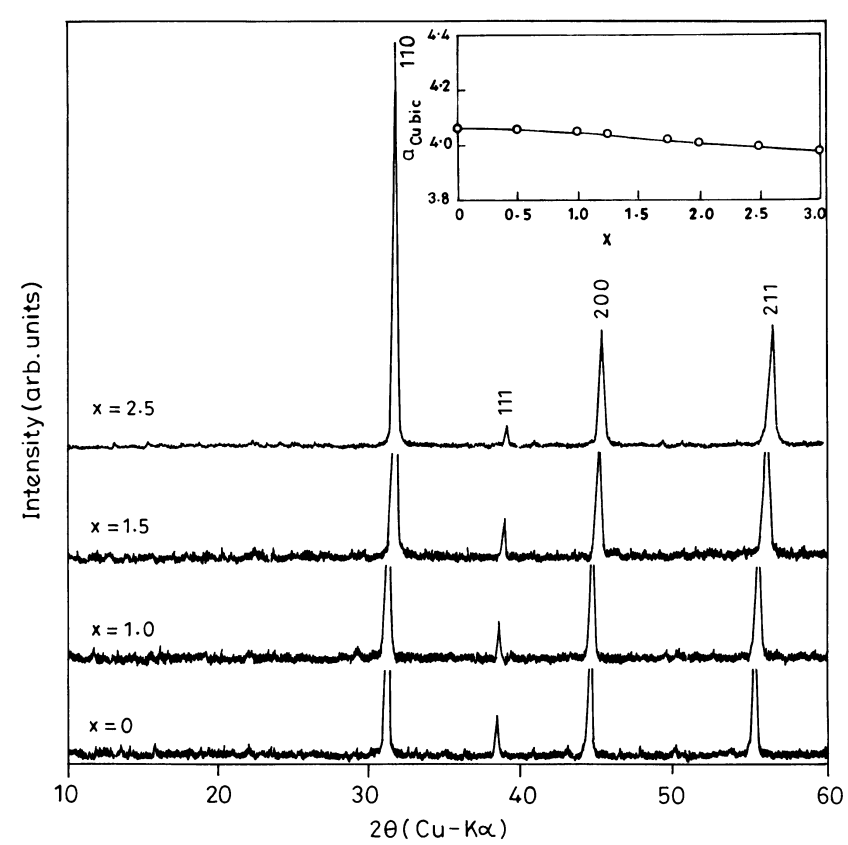

Figure 1. PXRD of $\mathrm{Ba}_{3-x} \mathrm{Sr}_{x} \mathrm{ZnNb}_{2} \mathrm{O}_{9}$ system sintered at $1200^{\circ} \mathrm{C}$. Inset shows the variation of lattice parameter with composition. found to melt, on sintering the disks above $1200^{\circ} \mathrm{C}$ (PXRD of the cooled mass from the melt shows the presence of $5-7 \%$ of $\mathrm{Ba}_{5-x} \mathrm{Sr}_{x} \mathrm{Nb}_{4} \mathrm{O}_{15}$ phase for all the compositions). Hence, a fresh set of disks was sintered at a lower temperature of $1200^{\circ} \mathrm{C}$ for longer times of $24 \mathrm{~h}$. However, the pure $\mathrm{Sr}_{3} \mathrm{ZnNb}_{2} \mathrm{O}_{9}$ phase $(x=3)$ did not melt
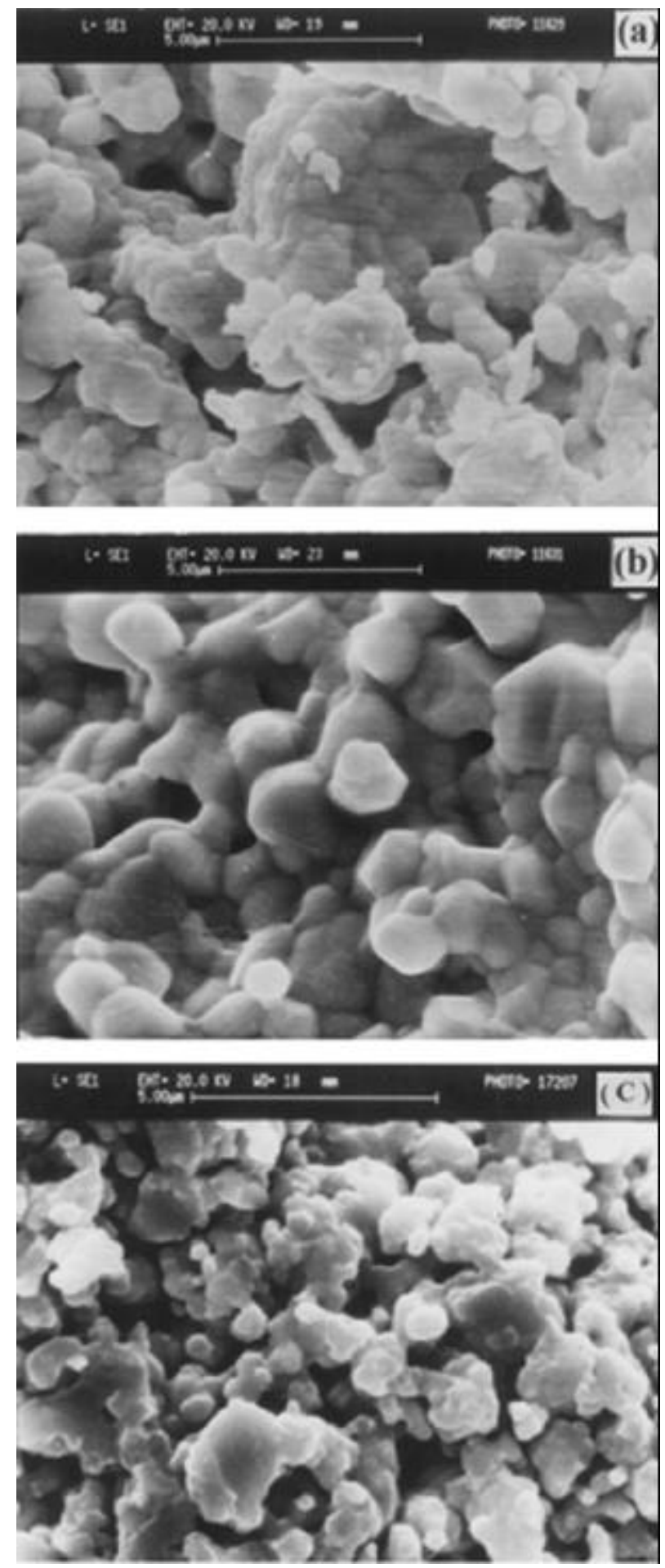

Figure 2. Scanning electron micrograph of $\mathrm{Ba}_{3-x} \mathrm{Sr}_{x} \mathrm{ZnNb}_{2} \mathrm{O}_{9}$ system sintered at $1200^{\circ} \mathrm{C}$. (a) $x=0$, (b) $x=1$ and (c) $x=3$. 
even at $1300^{\circ} \mathrm{C}$ and gave an ordered hexagonal structure with lattice parameters $a=5.646(6) ; c=6.907(3) \AA$. Except for the composition, $x=1$, which had about $6 \%$ of $\mathrm{Ba}_{5-x} \mathrm{Sr}_{x} \mathrm{Nb}_{4} \mathrm{O}_{15}$ (figure 2), all the other compositions led to monophasic oxides (figure 1) which retained the cubic structure. However, in an earlier study (Onoda et al 1982) on the related $\mathrm{Ba}_{3-x} \mathrm{Sr}_{x} \mathrm{ZnNb}_{2} \mathrm{O}_{9}$ system, sintered at $1500^{\circ} \mathrm{C}$ for $1 \mathrm{~h}$, no melting was reported and increase in 'Sr' concentration $(x \geq 0 \cdot 6)$ led to broadening of high angle lines in the X-ray diffraction pattern indicating the coexistence of both ordered and disordered phases. In our investigations for the $1200^{\circ} \mathrm{C}$ sintered samples we clearly observe sharp lines in the powder XRD pattern, which could be indexed on a single cubic cell. It may be noted that studies (Thirumal and Ganguli 2000) on $\mathrm{Ba}_{3-x} \mathrm{Sr}_{x} \mathrm{MgNb}_{2} \mathrm{O}_{9}$ (Mg-analogues of the above compositions) led to ordered hexagonal structures at $1000^{\circ} \mathrm{C}$ itself.

From the scanning electron microscopic studies on sintered disks $\left(1200^{\circ} \mathrm{C}\right)$, the particle size of the samples was found to be around 0.5 to $2 \mu \mathrm{m}$ for all the compositions studied (figure 2). The grains show an increase in size with $\mathrm{Sr}$ substitution till $x=1$. For $x=0$ composition, the grains are agglomerated, with diameter of the order of 0.5 to $1 \mu \mathrm{m}$. For the $x=1$ composition grains of around $2 \mu \mathrm{m}$ could be observed. The grains appear to be close to their melting temperature as several small fused grains with weakly visible grain boundaries were observed (figure $2 b$ ). These oxides could be sintered only till $1200^{\circ} \mathrm{C}$ since higher temperatures led to melting of the solids (except for $x=3$ composition which was sintered up to $1300^{\circ} \mathrm{C}$ ). The $x=3$ composition shows varying grain sizes between 1 and $2 \mu \mathrm{m}$ (figure $2 \mathrm{c}$ ). However, there was no sign of melting as observed in the $x=1$ composition.

Dielectric constant for the entire series of oxides in the above solid solution decreases with increasing frequency (figure 3). The dispersion in the dielectric constant is very low throughout the frequency range (till $500 \mathrm{kHz}$ )
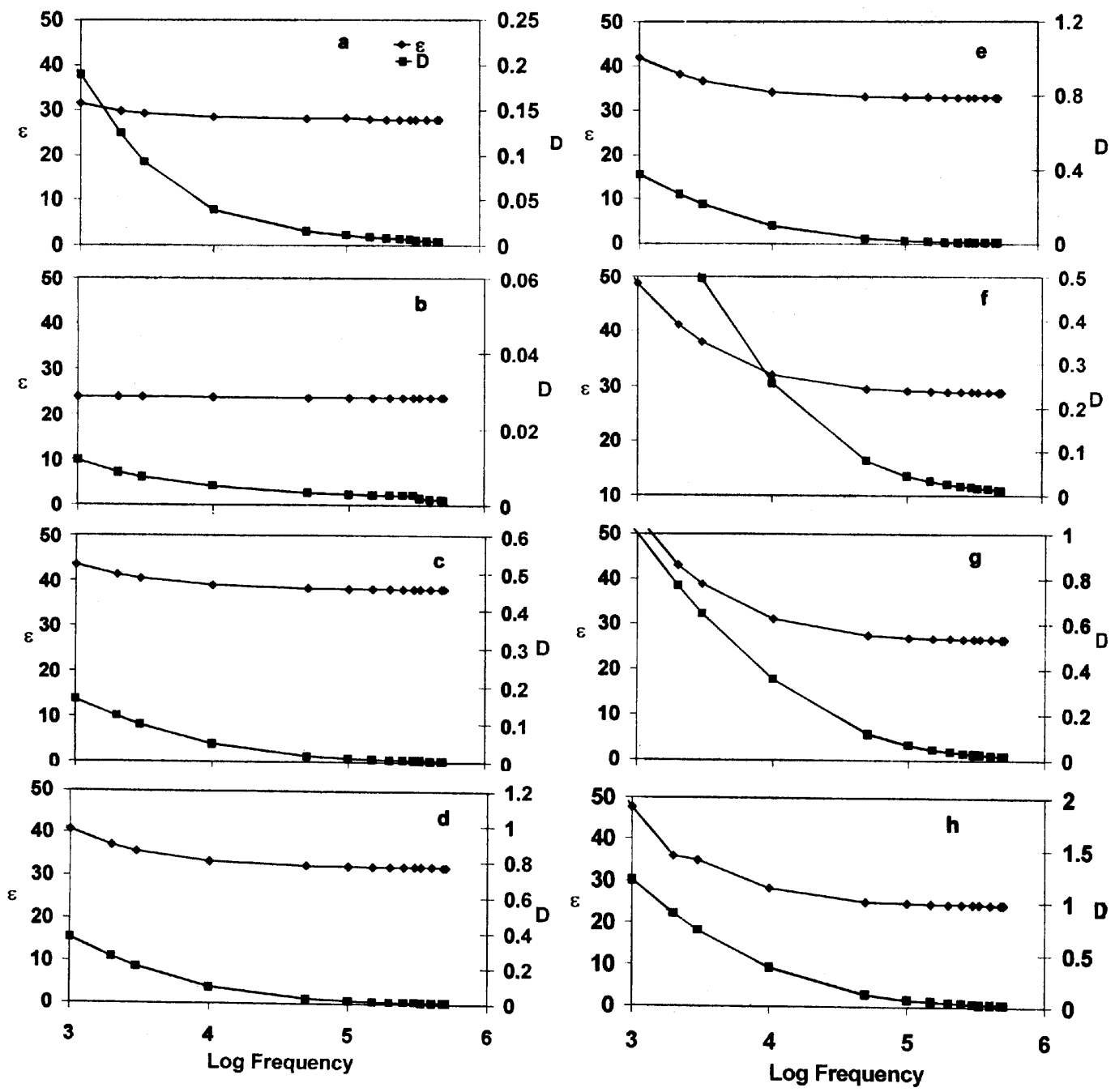

Figure 3. Variation of dielectric constant $(\varepsilon)$ and dielectric loss $(D)$ for $\mathrm{Ba}_{3-x} \mathrm{Sr}_{x} \mathrm{ZnNb}_{2} \mathrm{O}_{9}$ system sintered at $1200^{\circ}$ C. a. $x=0$, b. $0 \cdot 5$, c. 1, d. $1 \cdot 25$, e. $1 \cdot 5$, f. $1 \cdot 75$, g. 2 and h. $2 \cdot 5$. 
for compositions between $x=0$ and $x=1 \cdot 5$. There is considerable dispersion of the dielectric constant and dielectric loss in $\mathrm{Sr}$ rich compositions $(x>1.5)$ especially in the low-frequency region $(<50 \mathrm{kHz})$.

The variation of dielectric constant depends on the concentration of $A$-site substitution. The dielectric constant increases with strontium concentration, from $x=0$ to $x=1$, having a maximum value around 40 for the $x=1$ composition. With further increase of $\mathrm{Sr}$ concentration it decreases to $\sim 32$ (for $x=1 \cdot 25$ ) and it remains almost constant till $x=1 \cdot 75$. All the above values of the dielectric constant are for $500 \mathrm{kHz}$ frequency. Dielectric loss $(D)$ decreases with increasing frequency. However, it remains almost constant $(0.01)$ at $500 \mathrm{kHz}$ for the entire range of solid solution studied.

The above behaviour of the dielectric constant with composition showing a maximum around $x=1$ is also seen in earlier studies of $\mathrm{Ba}_{3-x} \mathrm{Sr}_{x} \mathrm{ZnNb}_{2} \mathrm{O}_{9}$ (Onoda et al 1982). These samples were sintered at $1500^{\circ} \mathrm{C}$ for $1 \mathrm{~h}$ and the maximum dielectric constant of 46 was observed at $x=1 \cdot 2$. In another study on the ' $\mathrm{Mg}$ ' analogue, $\mathrm{Ba}_{3-x} \mathrm{Sr}_{x} \mathrm{MgNb}_{2} \mathrm{O}_{9}$, a similar behaviour of a maximum in the dielectric constant at $x=1.5$ was observed (Lee et al 2001). It is believed that as ' $\mathrm{Sr}$ ' ions substitute ' $\mathrm{Ba}$ ' ions in the cubooctahedral sites of the perovskite-related structure the size of the oxygen octahedra decreases. Beyond a critical concentration (ranging from $x=1$ to 1.5 depending on the oxide family) there is an antiphase tilting of the oxygen octahedra (Colla et al 1993). The tilting of the octahedra lead to a decrease in the dielectric constant in Srrich compositions (beyond $x=1$ in our system).

\section{Conclusions}

Powder X-ray diffraction of $\mathrm{Ba}_{3-x} \mathrm{Sr}_{x} \mathrm{ZnNb}_{2} \mathrm{O}_{9}(0 \leq x \leq 3)$ solid solution shows cubic phase for all the compositions sintered at $1200^{\circ} \mathrm{C}$. Sintering at $1300^{\circ} \mathrm{C}$ led to hexagonal ordered structure for $\mathrm{Sr}_{3} \mathrm{ZnNb}_{2} \mathrm{O}_{9}$. However, other members of the family (partially melted), retained the cubic phase along with the formation of $\mathrm{Ba}_{5-x} \mathrm{Sr}_{x} \mathrm{Nb}_{4} \mathrm{O}_{15}$ secondary phase. Particle size increases with increase in strontium concentration. The dielectric constant for $1200^{\circ} \mathrm{C}$ sintered samples show variation between 28 and 40 at $500 \mathrm{kHz}$, with composition, with the maximum value of 40 for $x=1$ composition.

\section{References}

Colla E L, Reaney I M and Setter N 1993 J. Appl. Phys. 74 3414

Desu S B and O'Bryan H M 1985 J. Am. Ceram. Soc. 68546

Endo K, Fujimoto K and Murakawa K 1987 J. Am. Ceram. Soc. $70 \mathrm{C}-215$

Galasso F and Pyle J 1963 J. Phys. Chem. 671561

Galasso F, Katz L and Ward R 1959 J. Am. Chem. Soc. 81 820

Hong K S, Kim I T and Kim C D 1996 J. Am. Ceram. Soc. 79 3218

Kawashima S, Nishida M, Ueda I and Ouchi H $1983 \mathrm{~J}$. Am. Ceram. Soc. 66421

Lee H J, Park M P, Song Y W, Cho Y K, Nahm S and Byun J D 2001 J. Am. Ceram. Soc. 842105

Nomura S, Toyama K and Kanata K 1982 Jpn J. Appl. Phys. 21 L624

Onoda M, Kuwata J, Kanata K, Toyama K and Nomura S 1982 Jpn J. Appl. Phys. 211707

Plourde J K 1981 IEEE Trans. Microwave Theory and Tech. MTT-29 754

Roy R 1954 J. Am. Ceram. Soc. 27581

Shannon R D 1976 Acta Crystallogr. A32 751

Thirumal M and Ganguli A K 2000 Bull. Mater. Sci. 23495

Vincent H, Perrier C, Theritier P and Labeyrie M 1993 Mater. Res. Bull. 28951 